\title{
Fatal case of cryptococcal meningitis and pneumonia in HIV-infected child - case report
}

\begin{abstract}
Cryptococcosis is an infrequent but treatable opportunistic infection of HIV-infected children. The diagnosis of HIV in this case was not clear at admission but clinical history was consisted of several typical signs like body weight loss, recurrent temperature, episode of severe bacterial disease. In all patients with fever, headache, meningismus and CD4+T-lymphocyte deficiency should be suspected cryptococcosis.
\end{abstract}

Keywords: cryptococcus, meningitis, children, human immunodeficiency virus
Volume 6 Issue 4 - 2018

\section{Liudmyla Zakordonets, Vitalii lyvtushenko, Sergiy Kramarov}

Department pediatrics infectious diseases, Bogomolets National Medical University, Ukraine

Correspondence: Sergiy Kramarev, Chief of the Department of Children's Infection Diseases Bogomolets National Medical University, 23A Degtyarevskaya str. Kyiv, Ukraine, Tel +38-044483-74-62, Fax +38-044-483-38-4I, Email skramarev@ukr.net, Izakordonets2@gmail.com

Received: May 10, 2018 | Published: August 03, 2018
Abbrevations: CNS, central nervous system; HIV, human immunodeficiency virus; AIDS, acquired immuno deficiency syndrome; CM, Cryptococcal Meningitis; CSF, cerebro-spinal fluid; ESR, erythrocyte sedimentation rate

\section{Introduction}

Cryptococcosis is one of the most common infections in AIDS and disseminated cryptococcosis occurs in about one-third of AIDS patients. ${ }^{1,2}$ From 2 to $53 \%$ of AIDS patients develop cryptococcal meningitis as their first AIDS defining disease..$^{3-5}$ Among pediatric patients incidence of cryptococcal meningitis relatively rare and reported in range $0,85-2,97 \% .^{6-8}$ While disease is not common in children, it remains an important cause of morbidity and mortality. ${ }^{9}$

\section{Case}

A 14-year-old boy was admitted to our hospital with complaints of fever to $40,0^{\circ} \mathrm{C}$, severe headache, loss of appetites, vomiting. Over the preceding 60days, the patient had recurrent temperature, diarrhea, lost of $15 \mathrm{~kg}$ of body weight. Patient had a one episode of pyelonephritis a month ago. There was no history of any chronic illness. On admission clinical examination showed temperature of $38,5^{\circ} \mathrm{C}$, pulse rate90beats/min, blood pressure $-120 / 90 \mathrm{~mm} \mathrm{Hg}$, respiratory rate-20/min and physical examination revealed no respiratory and cardiovascular system abnormalities. All groups of lymph nodes were enlarged to $2,5 \mathrm{~cm}$, liver was enlarged to $2,0 \mathrm{~cm}$, spleen - to $5,0 \mathrm{~cm}$. Meningeal sings were positive. CITO test HIV $1 / 2$ (Pharmasco) was positive. CSF analysis: protein- $0.36 \mathrm{~g} / \mathrm{L}$, sugar- $2,39 \mathrm{mmol} / \mathrm{L}$, cell count $-5 \times 10^{6} \mathrm{cells} / \mathrm{L}$ (all - lymphocytes). Blood analysis: leukocytes count to $5,0 \times 10^{9} / \mathrm{L}$, with $10 \%$ bands, $67 \%$ segments, $13 \%$ lymphocytes, $4 \%$ eosinophils, and $6 \%$ monocytes, $\mathrm{Hb}-120 \mathrm{~g} / \mathrm{L}, \mathrm{ESR}-10 \mathrm{~mm} / \mathrm{hr}$. Liver function tests, kidney function tests, urine analysis were within normal levels.

On day 4 was worsening of general condition: appeared generalized tonic-clonic seizures, score of E4V5M6 on Glasgow Coma scale, pulse 59 beats $/ \mathrm{min}$, blood pressure $-144 / 88 \mathrm{~mm} \mathrm{Hg}$, respiratory rate$18 /$ min, persisted meningeal sings, decreased level of hemoglobin, erythrocytes, thrombocytes. Gram's stain of CSF and blood showed Gram-positive budding yeast-like structures (Figure 1). CSF and blood were cultured by standard procedures. Creamy white colonies were seen on Sabouraud dextrose agar medium. The identification and pathogenicity of Cryptococcus neoformans was established by growth at $37^{\circ} \mathrm{C}$, urease production and mouse pathogenicity test. Sputum was also cultured which was negative for Cryptococcus neoformans. Sputum sample for AFB staining was negative. Western Blot test for HIV-1 was positive. Chest X Ray and CT showed patchy nodular consolidation of right middle lobe. CD4 counts were 6,5 cell $/ \mathrm{mcL}$, CD4/CD8-0,05. The patient was given amphotericin B $(0.7-1 \mathrm{mg} /$ $\mathrm{kg}$ per day) and fluconazole $(12 \mathrm{mg} / \mathrm{kg} /$ day) from 3-rd day of hospital treatment.

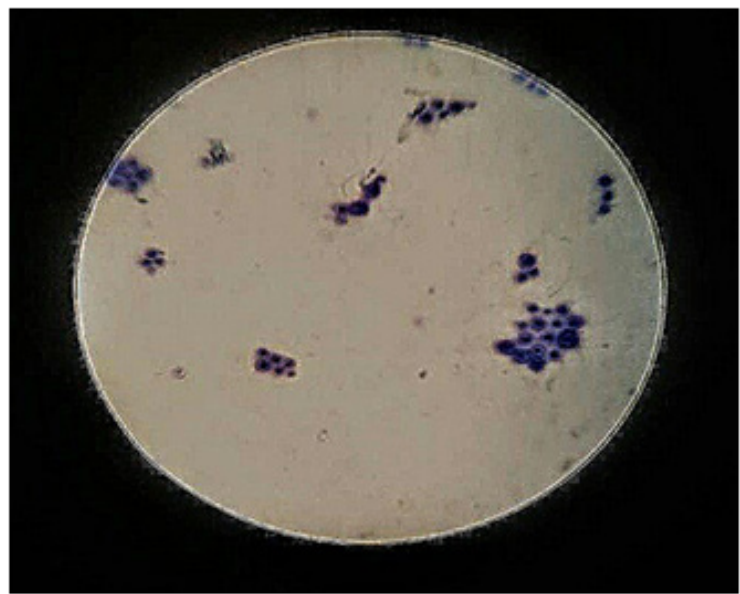

Figure I Gram's positive budding yeast-like structures seen in gram's stain of CSF.

Despite intensive treatment, signs of multiple organ dysfunction syndrome intensified. The therapy was unsuccessful: the patient died during the 23rd day of treatment.

\section{Discussion}

Cryptococcosis is an infrequent but treatable opportunistic infection of HIV-infected children. The diagnosis of HIV in this case was not clear at admission but clinical history was consisted of several typical signs like body weight loss and episode of severe bacterial disease. In view of all these findings, a sample for HIV was 
taken and found to be reactive. According to the available review cryptococcosis in children often presents with subtle and non-specific findings, such as fever and headache, and typically evolves over days to weeks with fever and headache. ${ }^{7}$ But clinical symptoms in this case were clearly indicative of meningitis and characterized by rapid neurological deterioration. CD4+T-lymphocyte deficiency is one of a main predisposing factors of cryptococcosis, especial meningitis, and in this boy CD4 count was found to be significantly decreased $(6,5 / \mathrm{mcL})$. Initial antifungal treatment of cryptococcal meningitis according to the recent guidelines includes amphotericin B (with or without flucytosine) and fluconazole. ${ }^{10}$ However, disease often be fatal even proper treatment is timely determined. ${ }^{11}$ This case also was associated with treatment failure despite early recognition of cryptococcal infection and using of approved medicines.

\section{Conclusion}

Cryptococcal meningitis may occurred as early presentation in children with HIV infection. In all patients with fever, headache, meningismus and CD4+ T-lymphocyte deficiency should be suspected cryptococcosis.

\section{Acknowledgements}

None.

\section{Conflict of interest}

The author declares no conflict of interest.

\section{References}

1. Hajjeh RA, Brandt ME, Pinner RW. Emergence of cryptococcal disease: epidemiology perspectives 100 years after its discovery. Epidemiol Rev. 1995;17(2):303-320.
2. Mitchell TG, Perfect JR. cryptococcosis in the era of AIDS - 100 years after the discovery of Cryptococcus neoformans. Clin. Microbio Rev. 1995;8(4):515-548.

3. Metta HA, Corti ME, Negroni R, et al. Disseminated cryptococcosis in patients with AIDS. Clinical, microbiological, and immunological analysis of 51 patients. Rev Argent Microbiol. 2002;34:117-123

4. S Bhagyabati Devi, Robinson Ningshen, Arvind G, et al. Prevalence of cryptococcal meningitis in patients of acquired immunodeficiency syndrome: A single center experience from regional institute of medical sciences. Journal of Medical Society. 2013;27(1):56-60.

5. Aslam S, Chandrasekhara P. Study of cryptococcal meningitis in HIV seropositive patients in a tertiary care centre. JIACM. 2009;10(3):110 115.

6. Likasitwattanakul S, Poneprasert B, Sirisanthana V. Cryptococcosis in HIV-infected children. Southeast Asian J Trop Med Public Health. 2004;35(4):935-939.

7. Abadi J, Nachman S, Kressel AB, et al. Cryptococcosis in children with AIDS. Clin Infect Dis. 1999;28(2):309-313.

8. Gonzalez CE, Shetty D, Lewis LL, et al. Cryptococcosis in human immunodeficiency virus-infected children. Pediatr Infect Dis J. 1996;15(9):796-800.

9. King J, Pana ZD, Lehrnbecher T, et al. Recognition and clinical presentation of invasive fungal disease in neonates and children. $J$ Pediatric Infect Dis Soc. 2017;6(Suppl 1):S12-21.

10. Perfect JR, Dismukes WE, Dromer F, et al. Clinical practice guidelines for the management of cryptococcal disease: 2010 update by the infectious diseases society of America. Clin Infect Dis. 2010;50(3):291-322.

11. Zheng H, Li M, Luo Y, et al. A retrospective study of contributing factors for prognosis and survival length of cryptococcal meningoencephalitis in Southern part of China (1998-2013). BMC Infect Dis. 2015;15:77. 